\title{
Multiple perforations of the jejunum caused by a migrated esophageal stent
}

A 17-year-old man presented to our emergency department with a 5-day history of persistent lower abdominal pain and nausea. His medical history was significant for a silicone-covered self-expanding metallic esophageal stent (MTN-SE-G-20/80, Nanjing, China) placed 3 weeks previously for a tracheoesophageal fistula. Plain abdominal and chest radiographs showed the stent lying in the inferior abdominal cavity (๑ Fig. 1).

There was no evidence of small-intestinal obstruction or perforation. Over the next 2 days the patient failed to improve and experienced progressive lower abdominal pain. A laparotomy revealed a roughly $10-$ $\mathrm{cm}$ long stent lying within the ascending colon. There were no signs of impaction and obstruction. Two perforations, approximately $0.2 \mathrm{~cm}$, with feces and pus were identified at the antimesenteric border of the jejunum proximal to the Treitz ligament. The perforations were closed in two layers following debridement and the stent was left in situ. At 6 days after the laparotomy, the stent was expelled per rectum ( $\bullet$ Fig. 2 ). The patient made an uneventful postoperative recovery.

A rare but serious complication of endoscopic stent placement is stent migration with resultant intestinal perforation [1 3]. Congenital anatomical abnormalities and fixation of the bowel because of previous postoperative eventration or adherence are common risk factors for bowel perforation because these conditions impede progression of the stent through the bowel [4].

In our case, fixation of the proximal jejunum to the Treitz ligament may have led to decreased mobility of the migrated stent, and the mechanical force exerted by the uncovered flared ends of the metallic stent against intestinal mucosa may have led to pressure necrosis and delayed perforation of the wall over a long period of time. We suggest that patients with a removable esophageal stent should be carefully evaluated and followed up. In addition, we advocate elective surgical removal of migrated metallic stents.

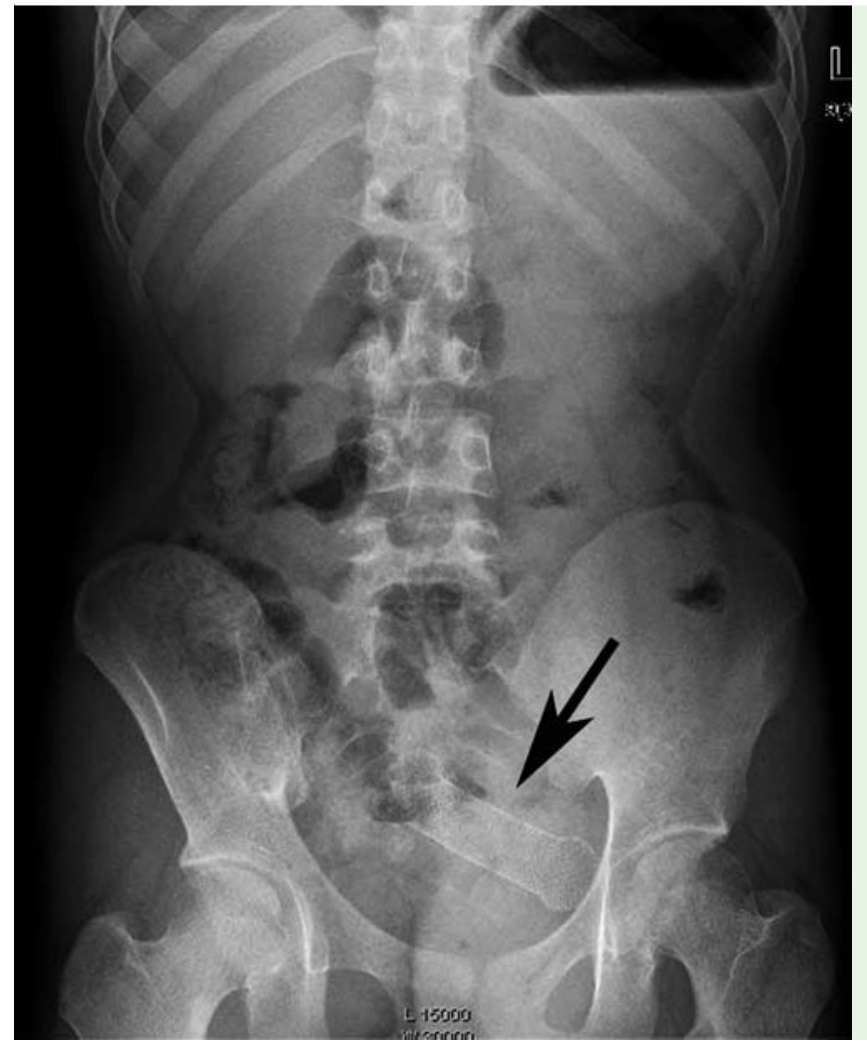

Fig. 1 Plain abdominal radiograph showing the stent in the inferior abdominal cavity.

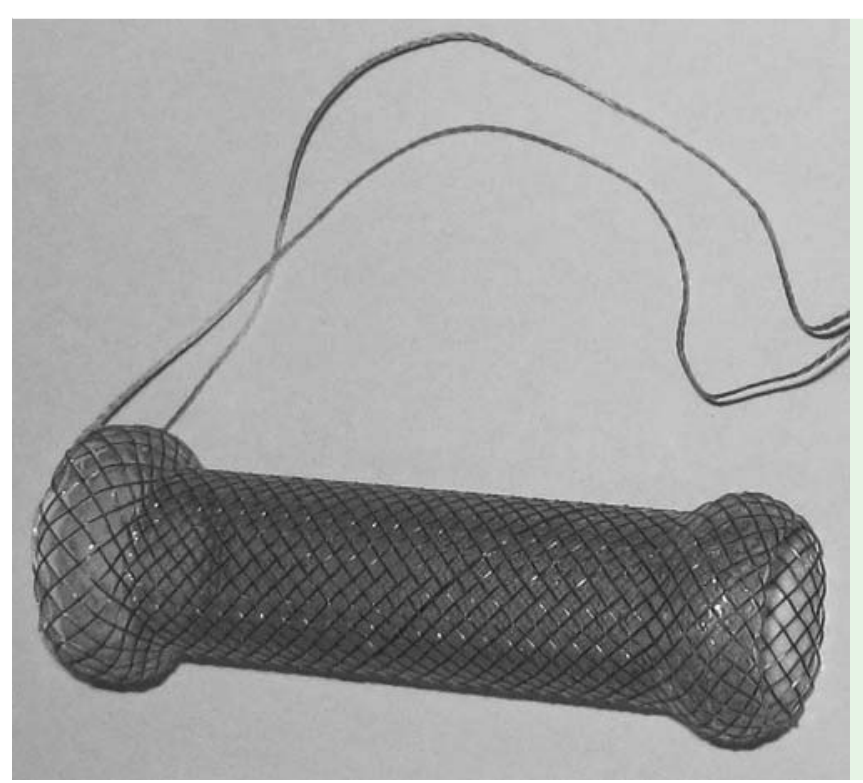

Fig. 2 The stent eliminated per rectum. 
Endoscopy_UCTN_Code_CPL_1AH_2AD

Competing interests: None

W. Zhang, W. J. Meng, Z. G. Zhou Institute of Digestive Surgery and Department of Gastrointestinal Surgery, West China Hospital, Sichuan University, Chengdu, China

\section{References}

1 Thumbe VK, Houghton AD, Smith MS. Duodenal perforation by a Wallstent. Endoscopy 2000; 32: $495-497$

2 Kim HC, Han JK, Kim TK et al. Duodenal perforation as a delayed complication of placement of an esophageal stent. J Vasc Intervent Radiol 2000; 11: 902-904

3 Reddy VM, Sutton CD, Miller AS. Terminal ileum perforation as a consequence of a migrated and fractured oesophageal stent. Case Rep Gastroenterol 2009; 3: 61 - 66

4 Saranga Bharathi R, Rao P, Ghosh K. Iatrogenic duodenal perforations caused by endoscopic biliary stenting and stent migration: an update. Endoscopy 2006; 38 : $1271-1274$

\section{Bibliography}

DOI $10.1055 / \mathrm{s}-0030-1256164$

Endoscopy 2011; 43: E145-E146

(c) Georg Thieme Verlag KG Stuttgart · New York . ISSN 0013-726X

\section{Corresponding author}

\section{Dr. Z. G. Zhou}

Institute of Digestive Surgery and Department of Gastrointestinal Surgery West China Hospital

No. 37 on Guo-Xue

Chengdu 610041

Sichuan Province

China

Fax: +86-28-85164035

zhou667@163.com 